\title{
Using Drama and Drama Techniques to Teach English Conversations to English as A Foreign Language Learners
}

Saman Masoumi-Moghaddam*

Department of English Language Literature, University of Tehran, Kish International Campus, Kish, Iran

Corresponding Author: Saman Masoumi-Moghaddam, E-mail: samanmasoumi@ymail.com

\section{ARTICLE INFO}

Article history

Received: April 17, 2018

Accepted: July 25, 2018

Published: November 01, 2018

Volume: 7 Issue: 6

Advance access: September 2018

Conflicts of interest: None

Funding: None

\begin{abstract}
The present study aimed to examine the ways in which drama and drama techniques and practices, as implemented in the English language classes and combined with pedagogical practices to teach and learn English conversation, can create the appropriate conditions that promote learning environments conducive for learning English conversations. The participants of this study were thirty undergraduate male and female students who had studied English at the secondary and high school levels at the public schools in Ardebil. They were classified into two groups including Control and Experimental groups. The two groups were administered a TestRetest evaluation to measure the targeted language skills that was to be taught to them. In order to collect the necessary data, two modern plays were taught and rehearsed in classroom context and then a retest were administered after the practice of these two modern dramatic discourse in the classroom. The different data-collecting techniques were used for the current research were participant observation (direct and indirect), and interviews. After analysing the data the results showed that there was no significant improvement in English competence of the Control group but the Experimental group revealed a tremendous achievement in their abilities in English conversations through the use of dramatic discourse.
\end{abstract}

Key words: Drama Techniques, Dramatization, English Language, Improvisation, Role-playing

\section{INTRODUCTION}

Sometimes the teaching of English language does not fulfill its goals. Even after years of English teaching, the learners do not reach the confidence of using English in and outside the class appropriately. Their output in the language learning is just limited in doing exercise based on the textbooks and in understanding grammar, but isolated with real communication among people. Real communication involves ideas, emotions, feelings, appropriateness and adaptability (Chauhan, 2004, p. 1).

The success of teaching speaking should be determined by many factors such as the material and the strategy applied by the teacher. Drama is an alternative strategy to improve students' competence in speaking. Drama and drama techniques can help students to learn and express themselves both through language spoken and language expression as well. Since the students are more active in verbal communication, drama is also a specific action to make the learning process more active, exciting, communicative, and contextual. Cheng (2007) stated that interactive dramas are a language learning activity in which each student in the class takes a distinct role with specific goals and then interacts with other students in the class to build alliances and complete common goals. Additionally, Maley and Duff
(1978) have pointed to the values and uses of drama: "Drama can help the teacher to achieve 'reality' in several ways. It can overcome the students' resistance to learning the new language. Therefore, it seems that existing strategies and methods for teaching English conversations to English as a Foreign Language (EFL) learners are inadequate for enhancing their competence for communication. Learners are forced to follow a set of artificial pedagogical curriculum for learning English conversations. Real life conversations like the one I propose (English drama) could be a perfect alternative for them".

\section{LITERATURE REVIEW}

\section{Teaching English Language and Acting}

Drama is a specific action to make the learning process more active, exciting, communicative and contextual. Acting is a way of learning by experiencing. Drama techniques, also, refer to all those techniques which accompany a dramatic discourse to help a better understanding and better performance of the text. Drama techniques integrate body, mind and emotions and motivate students by allowing them to use their own personalities and experiences as resources for language production (Maley and Duff, 1978, pp.6-7). McGregor, Tate 
and Robinson (1977), in Learning through Drama, stated that "Drama revolves around the process of behaviour, through interpersonal response. In acting-out, the individual himself is the prime medium of expression. Acting-out then is the exploration and representation of meaning using the medium of the whole person" (P.16). Drama forces students to interact because acting-out involves a "negotiation of meaning" (P.17).

\section{Literature and Culture}

According to Hall (2005), Literature promotes the psycholinguistic aspect of language learning as it focuses on form and discourse processing skills and improves vocabulary expansion and reading skills. Literature, in addition, has experienced a revival with the advent of communicative approach in language teaching as it provides learners with authentic, pleasurable and cultural material (pp.47-57). Cruz (2010) in his article entitled "The Role of Literature and Culture in English Language Teaching" notes that:

"Literature enhances ELT through elements such as authentic material, language in use and aesthetic representation of the spoken language, as well as language and cultural enrichment. It is with this last element that literature opens the door that leads to a wider and closer look on the culture (or cultures) where the target language is spoken" (P.1).

Hişmanoğlu (2005) also emphasizes the role that literature can play in teaching both basic language skills and language areas like vocabulary, grammar and pronunciation.

Most importantly, drama techniques are powerful means to motivate students' active involvement in learning as it brings excitement, fun and laughter into the classroom and encourages cooperation in a creative context. In this method, students have an already-made real-life discourse models and then they try to assimilate them while they speak.

\section{Drama and Teaching English Conversation}

There are several factors that interact in the process of acquiring language and learning new conceptual information through drama. One of the more important ones is "learning by doing". Drama enables students to learn new language and to understand new ideas by participating in different roles through which they use language to make sense of ideas.

Another important contribution to understanding the interaction between language acquisition and drama is the principle that learning is situated within interactions, particularly in drama. In this research, ELL students interact with each other and with the teacher, in ways that situate the meaning of those interactions. Richard Donato (2000) in Sociocultural Contributions to Understanding the Foreign and Second Language Classroom, states that: "learning and development, including foreign and second languages, is situated".

Faltis expresses, "classrooms become sites of situated cultural and language practices, with learners joining together, sometimes in conflict, to negotiate new and developing meanings and understandings" (ix). In this sense, drama theories have much in common with SLA theories, in that they can work together toward creating environments conducive to language learning.

\section{Research Approach \\ Constructivist theory}

Constructivist theory proposes that humans interpret behaviour and actions, and that's how they construct new knowledge. Constructivists also believe that humans behave purposefully. "Important complex behaviour like teaching and learning might be best understood as being constructed purposively by the subjects (both teachers and pupils) themselves, and cannot adequately be studied without accounting for meaning and purposes" (Magoon, 1977, pp.652).

Constructivists believe that knowledge exists within the learner and not exclusively in the environment itself. Knowledge is actively constructed by stimuli from the environment, resulting in the creation of cognitive structures in each learner. Therefore, the social interaction people engage in within an environment informs how language is acquired, learned, and eventually transformed to meet particular cultural needs.

\section{Sociocultural learning and social development theories}

According to Lantolf (2000) some symbolic tools, like languages, are used to "mediate and regulate our relationships with others and with ourselves and thus change the nature of these relationships" (p.1). In Sociocultural Perspectives on Human Learning, Hansen notes that: our ideas, values, emotions, behaviour patterns, even our perceptions are all cultural products, in that they are constructed in response to our social experience from the tendencies, capacities, and dispositions with which we are born (p.3).

Vygotsky (1989), with his theories of development through a sociocultural approach, concentrated on the connections between people and the cultural contexts in which they act and interact in shared experiences (p.44). He proposed that social interaction deeply influences cognitive and linguistic development. He believed in what he termed the "Zone of Proximal Development" (ZPD) which is "the distance between the actual development level as determined by independent problem solving and the level of potential development as determined through problem solving under adult guidance or in collaboration with more capable peers" (Mind, p.86). As related to education, a student can perform a given task through social interaction with a teacher or other well-informed students that he could not achieve on his own.

\section{Second language acquisition theories}

In theory and practice, there are two ways to become proficient in a second language: Through acquisition, where students pick up the second language through and become fluent in it by focusing on meaning and how to communicate meaningfully; or through learning, where students are instructed to pay attention to the form of the language, its grammar and rules, and how the rules can be used to form utterances for communication.

Learning a second language by paying attention to form and trying hard to create only accurate forms in the new language is the method of many English as a second language and foreign language teaching programs. This process 
is more in agreement with how adults consciously learn a new language. The students are instructed on the grammatical structures of the language, and they are taught new vocabulary to use within the grammatical structures, which are practiced over. The purpose of practicing the grammatical structures in the new language is for them.

\section{METHOD}

\section{Research Question}

- In what ways do drama and drama techniques help create conducive learning environments for the EFL students?

- How drama and drama techniques can enhance students' conversation skills?

\section{Participants of the Study}

The participants of this study were thirty undergraduate male and female students who had studied English at the secondary and high school levels at the public schools in Ardebil. They were classified into two groups including Control and Experimental groups. The two groups were administered a Test-Retest evaluation to measure the targeted language skills that was to be taught to them. They were divided into two target groups of students. Group A is considered as a Control group while Group B is considered as Experimental group.

\section{Instrument of the Study}

This study utilized two different syllabi for teaching English language skills. Group A (Control group) was exposed to a language syllabus that contained classical and traditional instructions and exercises on language skills with little or no exposure to literary discourse. Group B (Experimental group), on the other hand, was exposed to an experimental syllabus that included drama structure. This syllabus was designed mainly to develop English language conversation ability in the learners through literature or literary texts. The two dramatic texts that were used in this research were based on Arthur Miller's 'The Death of a Salesman' and Henrik Ibsen's 'A Doll's House' since the language the writers use in these two modern plays is not highly literary and it is like an everyday conversation.

\section{Procedure of the Study}

The two groups were administered a Test-Retest evaluation to measure the targeted language skills that was to be taught to them. These groups were selected for instruction for a complete eight-week term. This research was a qualitative case study that follows undergraduate students during a period of eight weeks. During this time, some exemplary and typical drama structures were used to teach English conversations. All participants were interviewed at several stages to obtain their reactions and responses as they participated in this project. To understand what students, particularly English students, thought about the use of drama and drama techniques to help them learn English conversations with cultural contents, their own words were used as direct feedback to inform the development and improvement of existing teaching practices. During this time, drama and drama techniques, practices and observed the participants interact with each other and with their teacher was incorporated. All of the participants periodically to obtain their reactions and responses as they participated in this project were interviewed.

For experimental group, two plays had chosen: Arthur Miller's 'The Death of a Salesman' and Henrik Ibsen's 'A Doll's House'. These two plays' language is highly simple, conversational and easy to follow. Before to start to use these two plays in the class, the topic and context of each of these was talked and explained plays to students so that they were quite familiar with them. Those lists of characters in the play were assigned to students to make them interested in participating actively in acting out their roles. Students were getting involved in preparing for their roles for ten minutes and then they were starting to read their own parts or at times when the conversation was short they were memorizing it.

\section{Data-collection}

\section{Participant Observation}

At first, the method that used for gathering data was observation. Direct observation in the classroom and indirect observation (what gathered through the use of a video camera or recording device) was used.

In direct observation, for every small details in the classroom such as how students respond to the piece of drama they are working; the degree of their interest; how body language helps them to convey their meanings; how they interact with each other and finally how they try to be appropriate in different contexts was supposed. In indirect observation which mostly focused on the accuracy of the discourse the learners, using and the degree of their fluency to see how drama and drama techniques that can affect these two main features was supposed. After videotaping or simply recording learners their language voices were transcribed and analysed.

\section{Interviews}

The second method I used to gather data in this study was through interviews. The interview was began by asking general questions about the participants, the school setting, their experiences and any other information about what they thought might be pertinent to the conversation, or information they felt they needed to convey.

\section{RESULTS}

\section{Data Analyses}

To perform this research, two English learning classes were chosen; in each class there were fifteen female students. In experimental group test- treatment-retest (role play) and in control group test- routine subjects- retest was implemented. 
After each drama session and interview has conducted, each one's documentation on the computer was transcribed, word by word. Each transcript with the corresponding time and date was labeled and each person talking was identified.

Other themes emerged from the interviews with the students: school life, personal life, how drama during class is used, learning content, using drama in other subjects, and future plans. The moments when students talk about anything related to the school, teachers, and classes was labelled as "School life", and, when students talk about their family, was labelled as "personal life."

\section{RESULTS}

The results of the Tests given out to the two groups show the outcome of this research project (Table 1, Table 2). The analysed data of transcribed interviews after doing this research showed that: learners have become significantly aware of context and they were very careful about being appropriate in different contexts. Reading authentic, contextual and lifelike material had created in them awareness about context and appropriacy. They even showed an extra ability of understanding how to switch to different registers in different context. For example, when they were talking to a friend they used informal and spoken language and they switched to formal language when they addressed me. This context awareness emerged in all 15 learners of this research.

The second element which was analysed was grammar and accuracy. Here though I had not taught and significant grammatical points in the class, all learners showed significant improvement in their grammar. I even can conclude that using drama in classroom context helps learners to acquire grammar rather than to learn it through artificial and traditional methods which teach them many boring rules with little outcome. Not only learners were speaking grammatically correct, they also gradually were moving from simple sentences to long and complex sentences.

The third element which I carefully analysed in learners utterances was vocabulary richness or (choice of words). Explicitly speaking, drama proved invaluable in this respect. I conclude that drama presented a very authentic, life-like and real model for learners to respond to. It was surprising to see how learners were picky and fastidious and to the point in their choice of words. They showed a perfect embededness and involvement with English language. By this I do not mean the learners were using many difficult vocabularies in their speaking but I mean that they knew and selected the right word for the right situation; and this in turn made their English beautiful.

The result of the control group showed a slight improvement in conversation skills regarding grammar, word power, and choice of words and appropriacy. On the other hand, Experimental group revealed significantly greater gain in language skills than the Control group in terms of grammar, word power, choice of words and appropriacy. This giant achievement is simply an obvious indicator to the fact that drama implementation has helped the Experimental group students to move up in their language learning ability in a significant way.

The critical analysis of the Re-test results proves that the Experimental group scored higher marks due to the usefulness of literary texts they studied during the whole term. This result indicates that the standard of the Experimental group has risen remarkably in the acquisition of the conversation skills taught to them. In other words, this result demonstrates that there are important gains to be achieved in including literature in the curriculum of the non-native learners of English.

The results also revealed that both literature and language teaching involve the development of feeling for language or spontaneous responses to the literary texts. Reading, practicing and interpreting dramatic texts help the learners to retain in memory useful quotations and phrases which they can use in their everyday speech. Moreover, the literary texts integrate linguistic competence with communicative competence by putting language into use in different social situations.

The results emphasize that a strong concerted effort has to be made for the inclusion of literary texts in EFL curriculum at all stages, whether primary, intermediate, or secondary. It is quite necessary on the part of the language teacher to provide learners with interesting plays from the finest treasures of English literature to make the reading of those texts and practice of them as a conversation model doubly interesting. Foreign language learners benefit from reading target-language literature because it gives practice in the pragmatic contextualization of linguistic expression.

In this study a very intimate relationship between educational goals and literary texts is established. The educationists, therefore, should make an appropriate selection from literature to meet the learner's needs, level, ability and interests at all stages. For example, for the primary pupils,

Table 1. Means and standard deviation of control and experimental group

\begin{tabular}{lcccc}
\hline Study groups & Number & Mean & Standard deviation & Standard error mean \\
\hline Control & 15 & 22.06 & 1.79 & 0.46 \\
Experimental & 15 & 39.08 & 2.51 & 0.64 \\
\hline
\end{tabular}

Table 2. Independent sample t-test between control and experimental groups

\begin{tabular}{lcccccc}
\hline t & df & sig (2-tailed) & Mean difference & Stdandard error difference & \multicolumn{2}{c}{ 95\% Confidence interval } \\
\cline { 3 - 7 } & & & & Lower & Upper \\
\hline-22.25 & 28 & 0.000 & -17.73 & 0.79 & -19.36 & -16.10 \\
\hline
\end{tabular}


simple one-act plays and games would be fun. Generally, young learners are usually motivated and willing to know a foreign language, so these literary texts will help them to acquire the language as a means of communication. Teachers of language should try to understand that the importance and effectiveness of teaching language lies in its spontaneous and impressive use by the learners.

In the light of the observations made in this research that drama plays a vital and stimulating role in the acquisition of English conversations. We can, therefore, safely conclude that drama can play a vital role in developing language skills among the non-native learners of English and helping them to use language for communicative purposes in the real world.

\section{FINDINGS AND DISCUSSION}

\section{Findings}

The analyses of the data related to the first research questions, In what ways do drama and drama techniques help create conducive learning environments for the EFL students?, showed that using drama in a language classroom is a good resource for language teaching. It is through the use of drama that learners become familiar with grammatical structures in exciting contexts and also learn about how to use the language to express, control and inform. The use of drama raises the students' awareness towards the target language and culture. In this context, the use of drama as a tool rather than an end goal gains significance in teaching a foreign language. Learners should make use of drama to improve their comprehension of life experiences, reflect on particular circumstances and make sense of their extra- linguistic world in a deeper way (Sarıçoban, 2004, p.15).

The analyses of the data related to the second research questions, How drama and drama techniques can enhance students' conversation skills, showed that Educational experiences, especially, in Iran; portray a school with a traditional classroom in which the teacher stands in front of the class to lecture while twenty to thirty students sit quietly before the teacher in individual seats. In such a class the interactions between teacher and student as well as between the students themselves would be minimal. These students are used to taking a passive role in the classroom listening to teacher-led lectures and waiting for direct guidance.

At the elementary level, acting out helps students to get involved actively and physically. In the early stages of language learning, students can demonstrate their comprehension of a command or question given by the teacher by responding in pantomime. They can act out the meaning of adjectives or verbs and give commands to each other to carry out. They can learn to do simple demonstrations, such as how to write and mail a letter, by first watching and listening to the teacher, practicing as a group by pantomime, then individually saying and doing the actions.

In selected class, this study started with monologues since it paves the way for dialogues. Students has recieved some famous extracts to be memorized and then acted out in front of other students in the class; this made them quite confident for later long performance.
In addition to monologues about themselves, students can also present dramatic monologues in which they take the role of a well-known person from the foreign language culture while the rest of the class listens and tries to identify the person. Dramatic monologues of this type could also represent characters from a story the class has read or even a movie. After doing monologues the students can progress to conversing in pairs with one student interviewing another. The interviewer takes notes and writes a report on his or her partner. To prepare for the interview, students can be given questions in the second language, questions in English which they translate to the second language, or they can make up their own questions with some help from the teacher.

As Freeman express, learners assimilate new information by shaping it to fit what they already know. Accommodation involves changing what we know in light of the new knowledge. In the same way, integration is a continual process of connecting new understandings to what we have already learned. Once we have integrated new knowledge, we use it comfortably. using drama as a technique to teach English conversation the teacher manages the theatrical possibilities and learning opportunities provided by the dramatic context from within the context by adopting a suitable role in order to: excite interest, control the action, invite involvement, provoke tension, challenge superficial thinking, create choices and ambiguity, develop the narrative, and create possibilities, for the group to interact in role.

The two groups were almost homogenous in their basic language skills in their test. The duration of the study was for a complete eight-week term in which the Control group was given instructions in language skills through a strictly language oriented syllabus with no literary discourse. The Experimental group was taught English conversation through exposure to dramatic texts.

At the end of the term when the instructions were complete, the two groups were given out Retest based on the components and study material that were designed for them.

\section{DISCUSSION}

One of the objectives that emerged in the process of conducting this research was to help to connect the gap between drama and ELL education when referring to teaching techniques for learning and acquiring a second language. Looking back at both the ELL strategies and the drama/theatre conventions which used in this research, and came across some similarities between both. In general, the strategies and techniques are alike, but have different terms to identify them. ELL teaching techniques target listening, speaking, reading, and writing skills, are including areas of grammar and pronunciation. ELL education uses a pack of techniques to achieve the acquisition and learning of a second language. Some of these techniques include, but are not limited to, music and songs, pictures, dialogues, journals, videos, and games. When compared to drama and theatre techniques, both involve some of the following: small group work, peer interaction, cooperation, active communication and kinesthetic learning. In this research, both sets of techniques seemed to work well together. 
Within the ELL field, Vivian Cook writes about the social communicative style and the information communicative style. The social communicative style "aims to give the students the ability to engage in conversations with people" (p.139), while the information communicative style acknowledges the importance of the subject matter within a conversation. She describes the information communicative style as one which "emphasizes the information that is transferred rather than the social interaction between the participants" (p.143).

In the drama field, and specifically in this research, the conventions used from Arthur Miller's 'The Death of a Salesman' and Henrik Ibsen's 'A Doll's House' incorporate both the opportunity for students to engage in conversation, and serve as a vehicle to illuminate the importance of the topics or themes discussed.

In this thesis, the fact that how drama and theatre techniques can encourage conversation since they can create situations in which the students can practice oral skills in the target language was discussed. Teachers can do this by having students engage in conversations because, not only are they practicing verbal skills and language knowledge, but because they can also learn oral skills from their conversational partner.

Using drama for teaching English conversation is also suggested since it has the power to encourage the concept of forming groups for cooperative learning. The idea of learning individually can be useful in certain situations, but many students benefit when working in groups. Not only do they learn how to work with others as part of a team, they can also see the different roles that emerge when working together. In drama education all the students in a classroom come from different backgrounds and have different experiences. Some might have similar backgrounds, but will always be different nonetheless. Connie Cochran expresses that: [cooperative learning makes sense for teachers who have LEP [limited English proficiency] pupils in their classes because all students are given frequent opportunities to speak and because a spirit of cooperation and friendship is fostered among classmates.

Another great advantage of using drama in teaching English conversation is the use of the body. Total Physical Response (TPR) is a tool used in language learning developed in the 1960 s by James J. Asher. TPR uses physical movements to create meaningful connections for language acquisition. Drama and theatre uses this potentiality of using body language to help learners in their learning process.

Finally, this research believed that teachers can depend a lot on learners' prior knowledge to help them achieve their educational goals. "All students, regardless of their proficiency in English, come to school with a valuable background of experience and knowledge on which teachers can capitalize" (Reed and Railsback,2003, p.27). The most important aspect of this is being able to use what is of interest to the student because she will be more willing to actively participate and engage with a topic that is relevant to her. For example, if the student is given a role she is not familiar with, or has little prior knowledge about that role, the chances of getting her to participate with the material is little and it becomes more difficult for her to feel comfortable participating because of the language barrier.

\section{CONFLICT OF INTEREST}

The authors declare that they have no conflict of interest.

\section{REFERENCES}

Chauhan, V. (2004). Drama Techniques for Teaching English. The Internet TESL Journal. Vol. X, No. 10, (3).

Cheng, M. (2007). Student Perceptions of Interactive Drama Activities. Journal of Interactive Drama. 2.3 (3).

Cruz, J. H. R. (2010). The Role of Literature and Culture in English Language Teaching. Linguistica aplicada. [Online] Available: http://relinguistica.azc.uam.mx/no007/ no07 art09.htm (Jan 7, 2018)

Donato, R. (2000). Sociocultural contributions to understanding the foreign and second language classroom. In Lantolf (ed.) (pp. 27-50).

Hall, G. (2005). Literature in Language Education. New York: Palgrave.

Hişmanoğlu, M. (2005). Journal of Language and Linguistic Studies: Teaching English Through Literature. 1, No. 1, (1).

Kramsch, C. (1996). The Cultural Component of Language Teaching. [Online] Available: http://tujournals.ulb. tu-darmstadt.de/index.php/zif/article/view/741/718

Krashen, S. D. (1982). Principles and practice in second language acquisition: Pergamon.

Lange, C., Linda M. \& Lange, D. L. (1985). "Doing the Unthinkable in the Second- Language Classroom: A Process for the Integration of Language and Culture" in Teaching for Proficiency, the Organizing Principle. Ed. Theodore V. Higgs. Lincolnwood, IL: National Textbook.

Lantolf, J. P. (2000). Introduction. Sociocultural Theory and Second Language Learning. (Ed.) James P. Lantolf. New York: Oxford UP, (pp. 1-26).

Project, S. C. D. T., McGregor, L., Tate, M., \& Robinson, K. (1977). Learning Through Drama: Report of the Schools Council Drama Teaching Project (10-16), Goldsmiths' College, University of London: Heinemann Educational for the Schools Council.

Magoon, A. J. (1977). Constructivist Approaches in Educational Research. Review of Educational Research. 47 (4), (pp. 651-693).

Maley, A., \& Duff, A. (1978). Drama Techniques in Language Learning: Cambridge University Press.

Sarıçoban, A. (2004). Using Drama in Teaching Turkish as a Foreign Language. Eurasian Journal of Educational Research. No.14, (pp. 13-32).

Reed, B., \& Railsback, J. (2003). Strategies and resources for mainstream teachers of English language learners. Portland, OR: Northwest Regional Educational Laboratory. [Online] Available: http://educationnorthwest.org/ sites/default/files/ell.pdf

Vygotsky, L. S. (1989). Concrete Human Psychology.” Soviet Psychology 27(2), (pp.53-77). 